Association for Information Systems AIS Electronic Library (AISeL)

Wirtschaftsinformatik Proceedings 2001

Wirtschaftsinformatik

September 2001

\title{
Travelling North: The Differing Research Cultures of Australia and Germany
}

Paula M.C. Swatman

Universität Koblenz-Landau, paula.swatman@uni-koblenz.de

Follow this and additional works at: http://aisel.aisnet.org/wi2001

\section{Recommended Citation}

Swatman, Paula M.C., "Travelling North: The Differing Research Cultures of Australia and Germany" (2001). Wirtschaftsinformatik Proceedings 2001. 67.

http://aisel.aisnet.org/wi2001/67

This material is brought to you by the Wirtschaftsinformatik at AIS Electronic Library (AISeL). It has been accepted for inclusion in Wirtschaftsinformatik Proceedings 2001 by an authorized administrator of AIS Electronic Library (AISeL). For more information, please contact elibrary@aisnet.org. 
In: Buhl, Hans Ulrich, u.a. (Hg.) 2001. Information Age Economy; 5. Internationale Tagung Wirtschaftsinformatik 2001. Heidelberg: Physica-Verlag

ISBN: 3-7908-1427-X

(C) Physica-Verlag Heidelberg 2001 


\title{
Travelling North: The Differing Research Cultures of Australia and Germany
}

\author{
Paula M.C. Swatman \\ Universität Koblenz-Landau
}

Summary: This invited paper discusses the discipline of Information Systems in Australia and German. Initially it describes the wide differences between the two academic cultures, endeavouring to identify the causes of these differences, as well as their implications. It then discusses the ways in which these two cultures handle the teaching of Information Systems and finally discusses the similarities and differences of the I.S. research cultures in Australia and Germany.

Keywords: Information Systems, research, culture

\section{Changing Cultures}

At the end of 2000 I moved from RMIT University in Melbourne to the University of Koblenz-Landau. This was an enormous change for me in almost every way imaginable:

- Linguistically - despite speaking French and Italian to quite respectable levels of fluency, I did not speak German at all at the time of my arrival (although things are improving on that front)

- Culturally - the processes of buying a house and daily living in Australia and Germany differ in a number of significant ways. Re-embedding oneself into a new culture is a very interesting and enlightening experience, throwing new light onto one's own original culture

- Academically - here the differences were perhaps the most noticeable: the Australian and German university systems are almost at opposite ends of the academic spectrum.

These personal changes were set within the context of changing roles for universities in both Germany and Australia - changes which are still very much underway.

Up until the late 1960's/early 1970's, the academic environment was very similar in most parts of the developed world. Universities were for the elite - those who could not cope with the standards expected and required simply fell by the wayside. Major changes occurred in almost all university systems at about that time, 
driven at least partly by the sweeping changes which were occurring in society more broadly.

The motivating factor in both cases was the concept of equality which, in Germany, led initially to the removal of academic regalia and formal graduation ceremonies - while in the English-speaking world (driven, in at least the US and Australia, by the Vietnam war and its dramatic effect upon middle class society), it led to a move away from 'scientific' principles towards the views of social scientists and the development of a more politically correct mindset. This change was followed during the 1980's by another change even more sweeping in its consequences - the move towards charging for education, with the inevitable result of corporatisation of the university sector - which led inevitably to the creation of an academic managerial elite. This, in turn, changed the goal of the successful academic from being the development of a research and teaching career into a search for senior administrative roles as the signal that one had 'made it' in the higher education sector.

Over time, therefore, the German and English-speaking university environments changed enormously. By the end of the $20^{\text {th }}$ century while, from the outside, life within a university appeared to be fairly similar in both German and Anglo academic sectors, the reality had become very different indeed.

\subsection{The Australian University Sector in the $21^{\text {st }}$ Century}

Over the period from the mid-1980's to the start of the $21^{\text {st }}$ century, government financial support for higher education in Australia fell dramatically. By 2000, government funds were providing rather less than $40 \%$ of fixed costs, with the result that universities had turned to fee-paying overseas students to fill the financial gap. All graduate education is now chargeable (from 2001 even doctoral students must pay full fees) and universities are increasingly tailoring their offerings to attract the greatest number of both local and overseas students. High levels of competition between universities means that several universities in one city may well be offering similar courses in attractive or fashionable fields, while less fashionable areas are under threat (at least two Australian universities, for example, have closed both their Physics and Philosophy departments).

The concept of the Wissenschaftliche Mitarbeiter/in is unknown in Australia doctoral students live on scholarships of around $\mathrm{A} \$ 15,000$ per annum (a little over DM 18.000), but do not have to undertake any additional work. From 2001, the number of scholarships provided by the government was reduced by one-third and all other doctoral students were required to pay fees of around $\mathrm{A} \$ 16,000$ per annum. The scholarship gap is currently being made up by the Universities themselves but, since they are already under severe financial pressure, this may not continue. 
These two factors mean that doctoral student numbers are not as high as they commonly are in Germany (except in the so-called 'Great Eight', the eight wealthiest universities which attract the majoriy of doctoral students, particularly in traditional fields such as engineering or the natural sciences). The majority of Australian academics teach long hours (as many as 16 hours of class contact per week in some universities), with marking of continuous assessment exercises and examination papers added to their load. The more senior staff (Professors and Associate Professors) are generally tasked with developing new, attractive fee-paying study programmes, and with raising money from industry or government in place of the heavy teaching load the more junior staff carry.

This last task is quite difficult because the Australian Research Council (ARC the equivalent of the DFG) funds fewer than 1 in 8 of the Large Grant applications submitted and has so far supported only a very small number of grants in Information Systems. Higher success rates are achieved with collaborative grants, where academic-industry partnerships pool commercial money with government grants. (An interesting comparison is that total government support for academic research in Australia in 2000 was less than the research income of the University of Arizona at Tucson over the same period.)

Despite the lack of funding and heavy workloads, however, Australian academics continue to perform remarkably well in terms of research publications, as this graph from the Australian Dept of Education, Training and Youth Affairs illustrates ${ }^{1}$ :

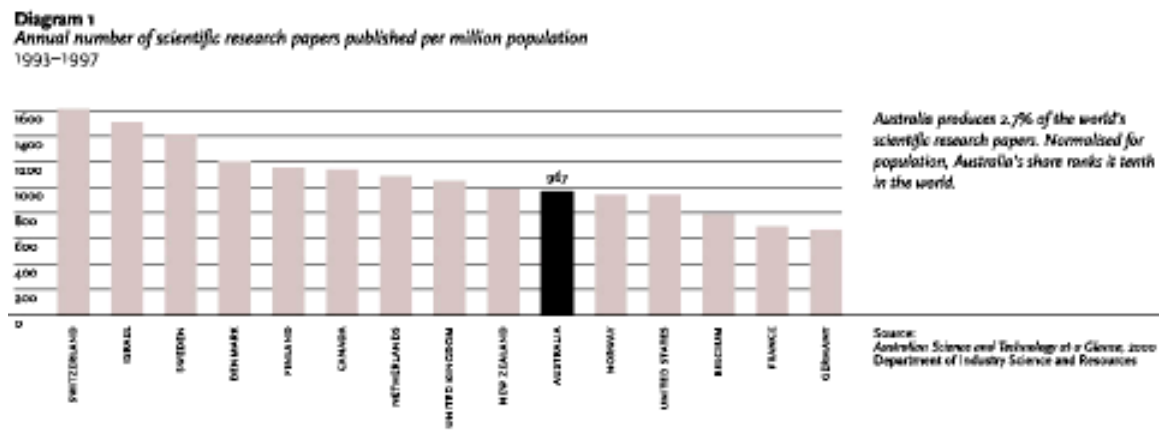

It is clear that Australian academics are performing very well under less than encouraging conditions - one can only wonder how well they would perform in an

1 ARC (2001) Australian Research Council Strategic Plan Introduction 2001, Australian Federal Dept of Education, training and Youth Affairs, Canberra, Australia. http://www.arc.gov.au/strat_plan/images/diagrams_1.JPG 
environment such as that of the US, where universities are, comparatively, enormously wealthy.

\subsection{German University Life - an Australian Perspective}

After just over five months in the German university environment, I am hesitant to speak with any certainty about what is or is not happening - and even more hesitant to make judgements on what I see. Some obvious differences, however, became apparent to me within weeks of my arrival in Koblenz.

\subsubsection{Administrative Roles}

The most noticeable difference is the lack of the managerial elite in the German university system. At present, German universities have not been corporatised (although the changes currently proposed look to me very much like the thin end of the wedge), and the result is that German academics see the role of professor as an end in itself, rather than as a means to an end (as in Australia, England, the US, Canada and New Zealand). In the Anglo world, there is a huge superstructure of Heads of Department/School, Deans, Pro Vice-Chancellors, Deputy Vice-Chancellors, Deputy Principals and Vice-Chancellors (many of these titles are different in the US, but the positions are approximately the same) who hold the real power in the academic system and who are paid significantly more than the professoriate generally.

An Australian professor, for example, earns around A\$95,000 (plus pension, plus a possible 'package' which can include car, mobile phone, corporate credit card, perhaps even a full-time research assistant, and other perks, usually in return for senior administrative work). A HoD/HoS would earn somewhere between A \$5,000-A \$15,000 and a Dean would earn an additional A $\$ 20,000$ on top of this. PVCs and DVCs can earn up to around A $\$ 180,000$, while some Australian ViceChancellors (these are the Presidents of Australian universities) earn between A $\$ 250,000-A \$ 500,000$ per annum. These positions are keenly sought and heavily contested.

In Germany, by contrast, the positions of Dekan and Pro-Dekan are seen more as a civic duty - which bring a huge additional workload, but little actual reward (except, perhaps, the knowledge that one has done one's duty). Even the Präsident and Vize-Präsident of most German universities earn little more than the average Professor, while undertaking an arduous administrative workload. 


\subsubsection{Work Groups}

The structure of Australian and German academic teaching and research units is completely different - and rather difficult to explain. The Australian structure is a traditional hierarchy:

- Head of Department/Head of School (this may or may not be a Professor)

- 1 or more Professors

- 1 or more Associate Professors

- $\quad$ several Senior Lecturers (this is the 'career' position for many academics - SLs do a significant amount of the day-to-day administration in the dept/school)

- $\quad$ several Lecturers (this group does the majority of the actual teaching).

The bulk of the teaching load is carried by the lecturers and senior lecturers who, in the newer universities, may not even have a doctorate. Doctoral and masters by research students undertake tutoring but do not usually lecture.

The comparison with the German concept of 'work groups', or even Institutes in those universities which have them, is clearly a very noticeable one.

\section{Information Systems Teaching and Research}

University education in the Anglo world is now entirely composed of unit-based curricula. Students therefore take their first (Bachelor's) degree in terms of subjects / units / courses (the names differ from place to place) and accumulate sufficient subjects at $1^{\text {st }}, 2^{\text {nd }}$ and $3^{\text {rd }}$ year level to take out a Pass degree. Assessment is largely by means of continuous assessment (assignments, essays, group work, etc) with examinations contributing less than $50 \%$ of the marks for most subjects studied. Students may choose to continue on to an Honours year, if their grades are high enough and, in this case, will undertake a further four subjects in a specialist field and will undertake a research thesis. Honours is the standard path to a doctorate in Australia (overseas students must provide evidence of ' $\mathrm{H} 1$ Equivalence' or, in other words, must show that they have achieved the equivalent of a $1^{\text {st }}$ Class Honours degree).

This contrasts strongly with the German Diplom, where students need only attend lectures in most subjects and essentially undertake two groups of examinations, frequently taking many years to complete their studies (although this is becoming less common). 
The other major difference lies in the approach to education - Australian universities have become far more vocational in their approach, with subjects including much less theory and more practice as time goes on.

\subsection{Information Systems Degrees}

The typical Australian Information Systems degree is very vocationally oriented: Australian universities seek industry accreditation for their programmes and courses, as well as seeking academic accreditation. Appendix A contains an example of a typical degree (this was selected more or less at random - my first two choices turned out to be under construction). They include a considerable amount of business studies and do not have very much in the way of computer science or software engineering content.

By contrast, German Wirtschaftsinformatik degrees are heavily oriented towards computer science (and are much more difficult to include in an appendix because they are not constructed on a unit-based foundation). Subject contents are more theoretic and there is significantly less in the way of tutorial and laboratory work provided (the typical Australian I.S. subject will include 2 hours of lectures per week and at least 2-3 hours of tutorials and supervised laboratory practical time).

\subsection{Information Systems Research}

In many ways, research differs less across the two countries than any other aspect of higher education. The greater emphasis on publication as a means of demonstrating success in Australia may mean that papers are produced a little faster than they often are in Germany - but otherwise activities are very similar. There are, however, a few ways in which research topics and methods of working differ:

- It is very common to find Australian academics publishing with their masters and doctoral students - something which, while by no means unheard of in Germany, is not nearly so common

- Applied research is much more common in the field of Information Systems in Australia than pure research. The majority of publications would relate to empirical investigations carried out with industry partners, frequently using case study, survey or action research as the research method

- Models are not nearly so frequently the basis for these empirical studies. While it is by no means uncommon to find Australian researchers using models, this is not the norm - qualitative research is probably more common than quantitative work (although there are obvious exceptions to this) 
- In line with the relative popularity of qualitative (and often interpretive) research approaches, generalisability of findings is not considered a particularly important goal for Australian I.S. research.

These differences may mean that topics for theses, research grants and papers differ somewhat across the two countries. As this track has shown, however, there is a great deal of common ground between researchers in the I.S. field - despite the huge differences between the overall academic systems and the rather different approaches taken to the study of Information Systems. 


\title{
3 Appendix A - A Typical Australian I.S. Degree Programme (Curtin University)
}

\author{
230010 v.3 Information Systems Major
}

\section{Introduction}

This specialisation caters for people interested in the design of information systems and the application of computer technology in a business and leads to careers as business analysts, systems analysts, information centre consultants, information managers in large or small business or government departments or information centres. Graduates meet the academic requirement for membership of the Australian Computer Society.

\section{Course Structure}

Year 1 Semester 2

Hrs/Wk Credits

$\underline{10808}$ v.1 Business Communication 101

13601 v.1 Introduction to Programming Concepts 102

10850 v.3 Marketing 100

$3.0 \quad 25$

$\underline{10605}$ v.2 Systems Modelling 102

Year 2 Semester 1

Hrs/Wk Credits

$\underline{10993}$ v.1 Business Statistics 101

$4.0 \quad 25$

10997 v.2 Database Systems 201

$4.0 \quad 25$

12610 v.1 Distributed Environments 201

$4.0 \quad 25$

13602 v.1 Systems Analysis and Design 201

$4.0 \quad 25$ 
100

Year 2 Semester 2

Hrs/Wk Credits

13008 v.1 Electronic Commerce (Internet Security) $3.0 \quad 25$ 304

OR

10995 v.2 Computer Security 302

$3.0 \quad 25$

$\underline{13603}$ v.1 Project Evaluation 202

$3.0 \quad 25$

11027 v.2 Systems Implementation 201

$4.0 \quad 25$

SELECT 1 ELECTIVE/S

25

100

Year 3 Semester 1

Hrs/Wk Credits

$\underline{02787}$ v.7 Information Analysis 311

$3.0 \quad 25$

$\underline{11008}$ v.2 Information Systems Project 391

$4.0 \quad 25$

$\underline{13605}$ v.1 Project Management 301

$4.0 \quad 25$

SELECT 1 ELECTIVE/S 25 100

Year 3 Semester 2

Hrs/Wk Credits

10829 v.1 Information Management 302

$3.0 \quad 25$

11009 v.2 Information Systems Project 392

$4.0 \quad 25$

SELECT 2 ELECTIVE/S 50 100 
